\title{
Microarray analysis distinguishes differential gene expression patterns from large and small colony Thymidine kinase mutants of L5 I 78 Y mouse lymphoma cells
}

\author{
Tao Han ${ }^{1}$, Jianyong Wang ${ }^{2}$, Weida Tong ${ }^{1}$, Martha M Moore ${ }^{2}$, James C Fuscoe ${ }^{1}$ \\ and Tao Chen*2
}

Address: ${ }^{1}$ Division of Systems Toxicology, National Center for Toxicological Research, U.S. FDA, Jefferson, AR, USA and ${ }^{2}$ Division of Genetic and Reproductive Toxicology, National Center for Toxicological Research, U.S. FDA, Jefferson, AR, USA

Email: Tao Han - tao.han@fda.hhs.gov; Jianyong Wang - jianyong.wang@fda.hhs.gov; Weida Tong - weida.tong@fda.hhs.gov; Martha M Moore - martha.moore@fda.hhs.gov; James C Fuscoe - james.fuscoe@fda.hhs.gov; Tao Chen* - tao.chen@fda.hhs.gov

* Corresponding author

from The Third Annual Conference of the MidSouth Computational Biology and Bioinformatics Society Baton Rouge, Louisiana. 2-4 March, 2006

Published: 26 September 2006

BMC Bioinformatics 2006, 7(Suppl 2):S9 doi:10.1 186/147I-2105-7-S2-S9

(C) 2006 Han et al; licensee BioMed Central Ltd.

This is an open access article distributed under the terms of the Creative Commons Attribution License (http://creativecommons.org/licenses/by/2.0), which permits unrestricted use, distribution, and reproduction in any medium, provided the original work is properly cited.

\begin{abstract}
Background: The Thymidine kinase (Tk) mutants generated from the widely used L5I78Y mouse lymphoma assay fall into two categories, small colony and large colony. Cells from the large colonies grow at a normal rate while cells from the small colonies grow slower than normal. The relative proportion of large and small colonies after mutagen treatment is associated with a mutagen's ability to induce point mutations and/or chromosomal mutations. The molecular distinction between large and small colony mutants, however, is not clear.

Results: To gain insights into the underlying mechanisms responsible for the mutant colony phenotype, microarray gene expression analysis was carried out on 4 small and 4 large colony Tk mutant samples. NCTR-fabricated longoligonucleotide microarrays of 20,000 mouse genes were used in a two-color reference design experiment. The data were analyzed within ArrayTrack software that was developed at the NCTR. Principal component analysis and hierarchical clustering of the gene expression profiles showed that the samples were clearly separated into two groups based on their colony size phenotypes. The Welch T-test was used for determining significant changes in gene expression between the large and small colony groups and 90 genes whose expression was significantly altered were identified $(p<$ 0.01 ; fold change > I.5). Using Ingenuity Pathways Analysis (IPA), 50 out of the 90 significant genes were found in the IPA database and mapped to four networks associated with cell growth. Eleven percent of the 90 significant genes were located on chromosome II where the Tk gene resides while only $5.6 \%$ of the genes on the microarrays mapped to chromosome II. All of the chromosome II significant genes were expressed at a higher level in the small colony mutants compared to the large colony mutants. Also, most of the significant genes located on chromosome II were disproportionally concentrated on the distal end of chromosome II where the Tk mutations occurred.

Conclusion: The results indicate that microarray analysis can define cellular phenotypes and identify genes that are related to the colony size phenotypes. The findings suggest that genes in the DNA segment altered by the Tk mutations were significantly up-regulated in the small colony mutants, but not in the large colony mutants, leading to differential expression of a set of growth regulation genes that are related to cell apoptosis and other cellular functions related to the restriction of cell growth.
\end{abstract}




\section{Background}

The mouse lymphoma assay (MLA) is used internationally for regulatory decision-making and it is the mammalian in vitro gene mutation assay preferred by the U.S. FDA, the U.S. EPA, and the International Committee on Harmonization (including the European, Japanese and U.S. pharmaceutical companies and regulatory agencies) [1-3]. The MLA is conducted using an L5178Y cell line that is heterozygous for the Tk gene. The assay detects forward mutation of the wild-type $T k$ allele $(T k 1 \mathrm{~b})$ located on mouse chromosome 11 [4]. In this assay, $T k$-deficient $\left(T k^{-}\right.$ /- or $T k^{0 /-}$ ) mutants of the L5178Y/Tk+/- mouse lymphoma cells are selected by the pyrimidine analog trifluorothymidine (TFT) because TFT inhibits division of the Tk competent $\left(\mathrm{Tk}^{+/-}\right)$cells that are capable of incorporating TFT into the DNA. The mutant cells cannot incorporate TFT into their DNA because of the Tk gene deficiency. Therefore, the mutants can grow and develop into colonies in the selective growth medium while the $T k$-competent cells are growth arrested and do not divide.

A striking feature of the $T k$ mutant colonies recovered in the MLA is the presence of two size classes of mutants. Immediately following their isolation, the cells in the large colonies grow at a normal rate, while cells in the small colonies grow slowly. The relative frequency of the two colony classes is mutagen dependent. Generally, clastogens induce more small colony mutants while point mutagens induce more large colony mutants [5-8]. It should be noted that many chemicals induce both small and large colony mutants.

It is important to obtain definitive information concerning the underlying molecular basis for the small and large colony mutant phenotype. This can be particularly important in a regulatory context. There is increasing interest in distinguishing between chemicals that cause point mutations and those that cause chromosomal mutants. The small and large colony Tk mutant phenotype was identified more than 30 years ago and there have been several hypotheses proposed to explain the difference between these two mutant types. The first one suggested that the small-colony mutants result from large scale damage to the chromosome $11 \mathrm{~b}$ on which the $T k^{+}$allele resides while large-colony mutants result from mutational events affecting the expression of only the Tk gene [9-11]. This hypothesis was expanded to state that small colony mutants are the consequence of intergenic lesions affecting the Tk gene and other putative growth control gene(s) that may or may not be on chromosome 11. Large colony mutants are the consequence of either intragenic lesions limited to the $T k$ gene or intergenic lesions that do not affect the growth control gene $[12,13]$. So far, the growth control gene or genes have not been identified. Further analysis using microsatellite markers on chromosome 11 demonstrated that both large and small colony mutants can apparently have relatively large alterations of chromosome $11 \mathrm{~b}$ $[14,15]$. Also, it is clear that the entire chromosome $11 \mathrm{~b}$ is lost in some large colony mutants [15]. Another possible hypothesis, demonstrated in other cell types, invokes a process of chromosome damage and repair. In this model, a cell with chromosome damage would suffer arrested growth until the cell repairs the damage $[16,17]$. None of these hypotheses, however, can fully explain the difference between the small and large colony phenotypes because the molecular analysis of mutants (primarily microsatellite analysis) does not reveal a clear cut distinction in the degree of "damage" between small and large colony mutants. That is, the fundamental mechanistic difference(s) between the small and large colony mutant phenotypes has not been elucidated using the available analytical techniques.

The advent of gene microarrays permits the analysis of gene expression for thousands of genes simultaneously in biological samples of interest, permitting functional interpretation of the transcriptome state of any given cell type at a particular physiologic state $[18,19]$. These cellular mRNA expression profiles yield global genomic fingerprints that identify the biological state of that cell. Molecular profiling has rapidly become an effective approach to further understanding of the phenotypes of tumor cells $[20,21]$. Because the colony size of $T k$ mutants is determined by the growth rate of mutant cells, it would be expected that there would be some difference in the expression levels of one or more specific growth regulation genes. Microarray analysis should allow us to measure gene expression in large and small colony mutants and discern possible mechanisms that lead to the two phenotypes based on the differences between the gene expression profiles.

ArrayTrack software developed at the National Center for Toxicological Research provides an integrated solution for managing, analyzing, and interpreting microarray gene expression data. It is MIAME (Minimum Information about a Microarray Experiment) supportive for storing both microarray data and experiment parameters associated with a pharmacogenomics or toxicogenomics study. Using ArrayTrack, users can easily select a normalization method and a statistical method applied to a stored microarray dataset to cluster genes into different groups according to expression profiles, to determine a list of differentially expressed genes (significant genes), and to link the gene list directly to pathways and gene ontology for functional analysis. ArrayTrack is being integrated and further refined at the U.S. FDA as a review tool for the pharmacogenomics data submission program http:// www.fda.gov/nctr/science/centers/toxicoinformatics/ 


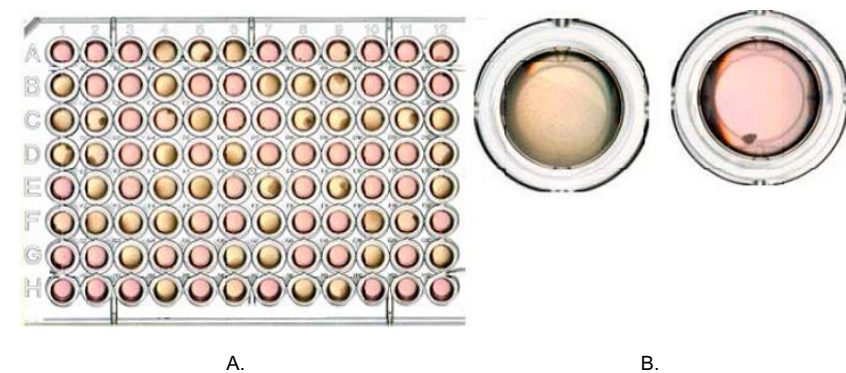

Figure I

Large and small colony Tk mutants in TFT selective medium. A. shows different size of colonies in a 96-well plate and B. displays a typical large colony mutant and a typical small colony mutant.

ArrayTrack/index.htm. ArrayTrack is also freely available to public [22].

In this study, previously isolated small and large $T k$ mutants were evaluated for differences in gene expression using microarray technology. We used this approach to address the following 4 questions: (1) whether microarray analysis using ArrayTrack could distinguish the two Tk mutant phenotypes; (2) whether microarray analysis could identify candidate genes that might contribute to the phenotype difference; (3) whether genes altered in their expression might be localized on chromosome 11 near the Tk gene; and (4) whether the results might provide insight into the underlying mechanisms responsible for the two types of mutants. For this analysis, we selected 4 small and 4 large colony mutant samples from a previously conducted 3'-azido-3'-deoxythymidine (AZT)-treatment [23]. These mutants were selected because they all showed the same microsatellite pattern. They were LOH for both Tk and D11Mit42 (see Figure 2). We used this strategy for the mutant selection so that we could determine if the microarray approach, which evaluates individual gene expression, would provide a level of resolution not provided by the microsatellite analysis. We found that

\begin{tabular}{ccccccccc}
\hline Agl2 & 42 & 59 & 36 & 29 & 22 & 20 & 19 & 74 \\
\hline 78.0 & 72.0 & 58.5 & 47.6 & 40.0 & 25.0 & 20.0 & 13.0 & $0.0 \mathrm{cM}$ \\
\hline$\circ$ & $\circ$ & $\bullet$ & $\bullet$ & $\bullet$ & $\bullet$ & $\bullet$ & $\bullet$ & $\bullet$ \\
\hline
\end{tabular}

\section{Figure 2}

The loss of heterozygosity $(\mathrm{LOH})$ pattern of all mouse lymphoma Tk mutants ( 4 small and 4 large colony mutant samples. The codes in the upper row are microsatellite loci on chromosome II. The numbers in the middle row are the distances from the top of the chromosome to the locus in $\mathrm{cM}$ (centimorgan). The symbol $\bigcirc$ indicates $\mathrm{LOH}$ and $\mathrm{O}$ indicates that the locus retains heterozygosity. microarray analysis using ArrayTrack distinguished the two different cellular phenotypes and identified a set of candidate genes that are responsible for the colony size phenotypes. Also, the expression of a high proportion of genes located near the $T k$ gene on chromosome 11 was differentially altered between the large and small colony mutant samples, which might be the original reason for the formation of two different sizes of colony mutants.

\section{Materials and Methods \\ Cells and culture conditions}

L5178Y/Tk+/--3.7.2C mouse lymphoma Tk-deficient mutants were grown according to the methods described by Chen and Moore [4]. Briefly, the basic medium was Fischer's medium for leukemic cells of mice with Lglutamine (Quality Biological Inc., Gaithersburg, MD) supplemented with $10 \%$ heat-inactivated horse serum, pluronic F68 $(0.1 \%)$, sodium pyruvate $(1 \mathrm{mM})$, penicillin $(100 \mathrm{U} / \mathrm{ml})$, and streptomycin $(100 \mu \mathrm{g} / \mathrm{ml})$. The cultures were maintained in a humidified incubator with $5 \% \mathrm{CO}_{2}$ in air at $37^{\circ} \mathrm{C}$. Unless otherwise noted, all culture supplies were purchased from Invitrogen Life Technologies (Carlsbad, CA).

\section{Selection of large and small colony Tk mutants and expansion of mutant cells}

Large and small colony mutants were selected from a series of mutants isolated following AZT treatment [23]. An example of large and small colonies in selective medium in 96-well plates is shown in Figure 1. The mutants were selected based on the considerations described in the introduction. All mutants showed the same microsatellite $\mathrm{LOH}$ pattern ( $\mathrm{LOH}$ at $\mathrm{Tk}$ and D11 Mit42 - see Figure 2) indicating that the chromosome alteration might occur at the $T k$ locus and extend up to $58.5 \mathrm{cM}$.

In addition, only mutants whose growth rates were relatively stable were chosen for microarray analysis of gene expression. The average doubling time for the large colony mutants was $9.6 \pm 0.2$ hours while the average doubling time for the small colony mutants was $17.5 \pm 0.4$ hours $(p$ $<0.001$, Student T-test).

\section{RNA Isolation and cDNA Labeling}

Total RNA was extracted from mutants whose cells were collected at log stage of growth using Qiagen RNeasy kits with on-column DNase digestion. The concentration and quality of RNA samples were measured by a spectrophotometer and an Agilent 2100 Bioanalyzer (Agilent, Palo Alto, CA). All the RNA samples were stored at $-80^{\circ} \mathrm{C}$ until used for microarray analysis.

The aminoallyl-indirect labeling protocol by The Institute for Genomic Research (TIGR, Rockville, MD) was fol- 
lowed with a few modifications. Briefly, $10 \mu \mathrm{g}$ of total RNA was primed with $6 \mu \mathrm{g}$ of random hexamer primers (Invitrogen, Carlsbad, CA) in a final volume of $16.5 \mu \mathrm{l}$. The RNA was reverse-transcribed in a $30 \mu \mathrm{l}$ reaction containing $0.5 \mathrm{mM}$ dATP, dCTP, dGTP, $0.3 \mathrm{mM}$ dTTP (Invitrogen) and $0.2 \mathrm{mM}$ aminoallyl-dUTP (aa-dUTP, Ambion), $40 \mathrm{U}$ RNase inhibitor (Invitrogen), $400 \mathrm{U}$ Superscript II (Invitrogen), $10 \mathrm{mM}$ DTT and $1 \mathrm{X}$ first strand buffer at $42^{\circ} \mathrm{C}$ for 2 hours to generate aminoallyl-labeled cDNA. The purified aminoallyl-cDNA was coupled with either Cy3 or Cy5 monoreactive dyes (Amersham Pharmacia, Piscataway, NJ). Uncoupled dyes were removed by QIAquick PCR purification kit. cDNA yields and dye incorporation efficiencies were determined using a NanoDrop spectrophotometer. A reference design was used in which RNA sample from each large or small colony mutant was labeled with Cy5 and paired with Mouse Universal Reference RNA (Stratagene, La Jolla, CA) labeled with Cy3.

\section{Hybridization and imaging}

Pairs of Cy3 and Cy5 labeled cDNAs were dissolved in 60 $\mu \mathrm{l}$ of hybridization buffer ( $5 \times$ SSC, $0.1 \%$ SDS with $27 \%$ formamide) and incubated with a mouse $20 \mathrm{k}$ oligonucleotide microarray that was fabricated in-house at the NCTR using oligonucleotides from MWG, Inc. (High Point, NC). The hybridization was performed in hybridization cassettes (ArrayIt, Sunnyvale, CA) in a water bath at $50^{\circ} \mathrm{C}$ for 16-18 hours. The slides were then washed in pre-warmed $\left(30^{\circ} \mathrm{C}\right) 2 \mathrm{X}$ SSC (containing $0.1 \%$ SDS) for 5 minutes, $1 \mathrm{X}$ SSC for 5 minutes, and 0.5X SSC for 5 minutes. The hybridized slides were dried immediately by centrifugation and scanned with a GenePix 4000B scanner (Axon Instruments, Sunnyvale, CA) at $10 \mu \mathrm{m}$ resolution. The resulting images were analyzed by measuring the fluorescence of all features on the slides using the GenePix Pro 6.0 software (Axon Instruments). The median fluorescence intensity of all the pixels within one feature was taken as the intensity value for each feature.

\section{Data analysis}

The raw data were imported into ArrayTrack (NCTR/FDA) and normalized using Total Intensity Normalization after subtracting backgrounds. Expression ratios (sample/universal RNA) from 8 arrays (4 large colony and 4 small colony mutant RNA samples) were log2-transformed. The logged data were used for principal component analysis (PCA), hierarchical cluster analysis (HCA), and statistical analysis for identifying genes that were differentially expressed in large versus small colony mutants. The Welch T-test was used for determining significant changes in gene expression between the large and small colony mutant groups. Significant genes were selected with a cutoff of $p<0.01$ and fold change $>1.5$. The selected genes were further analyzed for their functions and networks using Ingenuity Pathway Analysis (IPA, Ingenuity Systems Inc., Redwood City, CA). Information on genes' chromosome locations were obtained using Gene Library within ArrayTrack.

\section{Results \\ Principal component analysis and hierarchical clustering of the gene expression profiles}

Genome-wide expression profiles for $8 T k$ mutant samples were generated using the mouse oligonucleotide microarray. Principal components analysis (PCA) within ArrayTrack was used to carry out an examination of the relationship among the samples (Figure 3 ). A separation between large and small colony mutants was clearly observed. The large colonies are more tightly grouped together while the small colonies more loosely grouped. Hierarchical Cluster Analysis (HCA) using ArrayTrack also revealed distinct grouping of the mutant samples according to their colony size, suggesting that gene expression patterns are different between the large and small colony mutants (Figure 4).

\section{Identification of differentially expressed genes between large and small colony Tk mutants}

Welch T-test was used for determining significant changes in gene expression between large and small colony mutant groups. A volcano plot for differentially expressed genes between large and small colony mutants is shown in Figure 5. A group of 90 genes was found to be differentially expressed with a cutoff $(p<0.01$ and fold change $>$ $1.5)$. Among the 90 genes, 15 genes were up-regulated and 75 genes were down-regulated when the gene expression ratios in large colony mutants were compared to those in small colony mutants (large/small). A complete list of these genes can be found in Table 1 . There were 431 genes whose $p$-value was smaller than 0.01 without fold-change cutoff and 1034 genes that have a fold-change greater than 1.5 without considering the $p$-value.

\section{Pathway analysis of the significant genes}

The selected genes were analyzed for their functions using IPA that is integrated with ArrayTrack. Among the 90 genes, 50 genes were mapped to the IPA database and were used for functional analysis. The 50 genes were mapped to four different networks in the IPA database (Table 2). The scores for all of the mapped networks were higher than 19, indicating that the networks selected were not due to random chance alone. (A score of 3 or greater was considered significant at $p<0.001$ level). These networks were associated with the following pathways: gene expression, cell signaling, lymphatic system development and function, cellular growth and proliferation, cell death and cancer. 


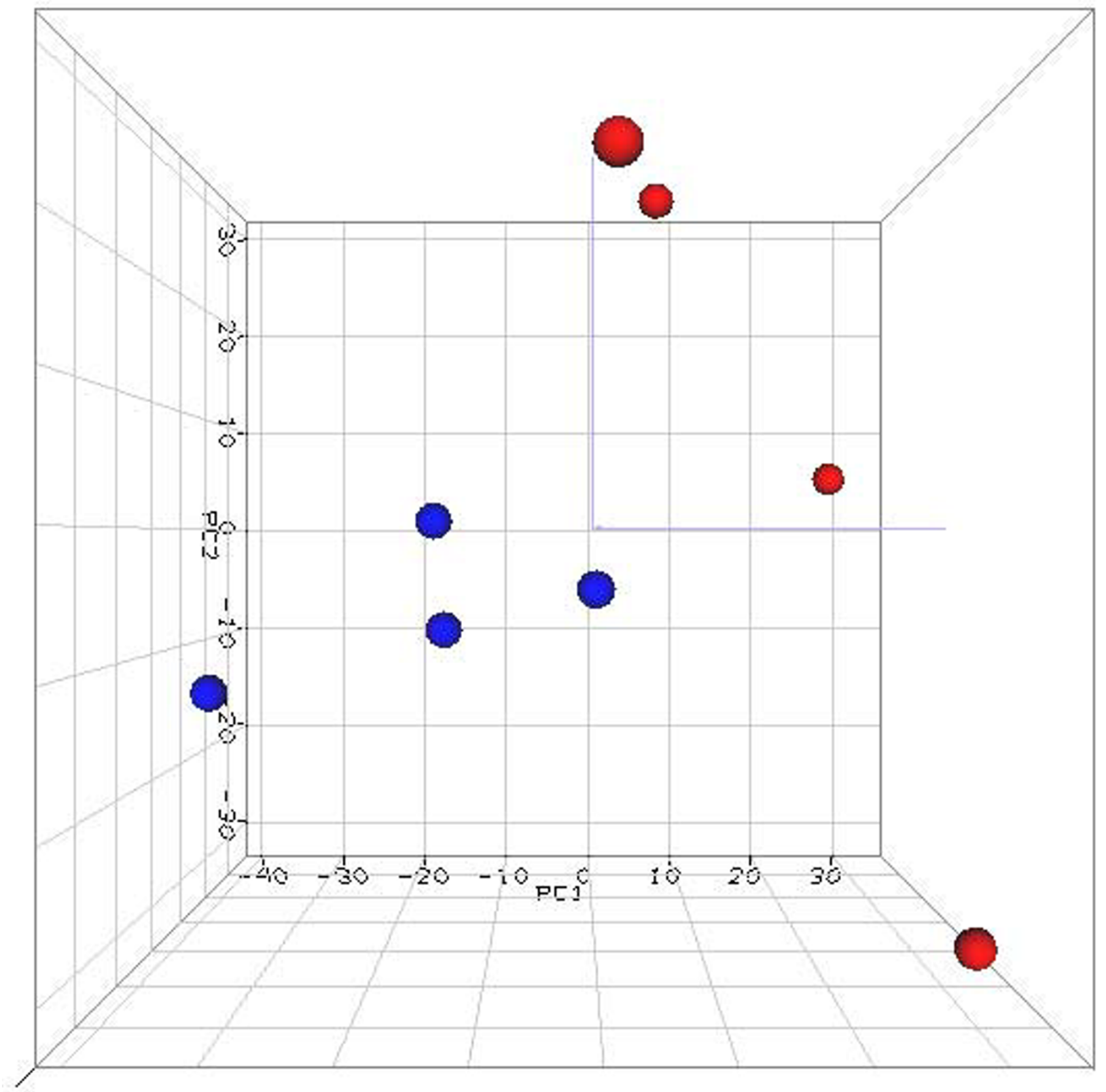

Figure 3

Principal component analysis (PCA) 3D view for gene expression profiles from 8 large and small colony Tk mutant samples. The PCA is based on log2 ratios and the expression profiles are across all the 20,000 genes in the microarrays. The blue and red dots indicate large and small colony mutants, respectively. The first three principal components are plotted. The captured variances of PCI (first principal component), PC2 (second principal component) and PC3 (third principal component; the label is not shown) were $25.5 \%, 17.4 \%$, and $15.5 \%$, respectively.

\section{Significant genes located on chromosome II}

The mouse lymphoma mutants are identified and isolated because they have mutation(s) that involve the Tk gene that is located at the distal end of chromosome 11. The mutation can occur solely within the Tk gene or it may also involve other genes on chromosome 11 . While the underlying difference between the small and large colony mutants has remained elusive, it is clear that the slow growth of the small colony mutants must be caused by an alteration in the expression of one or more genes related 


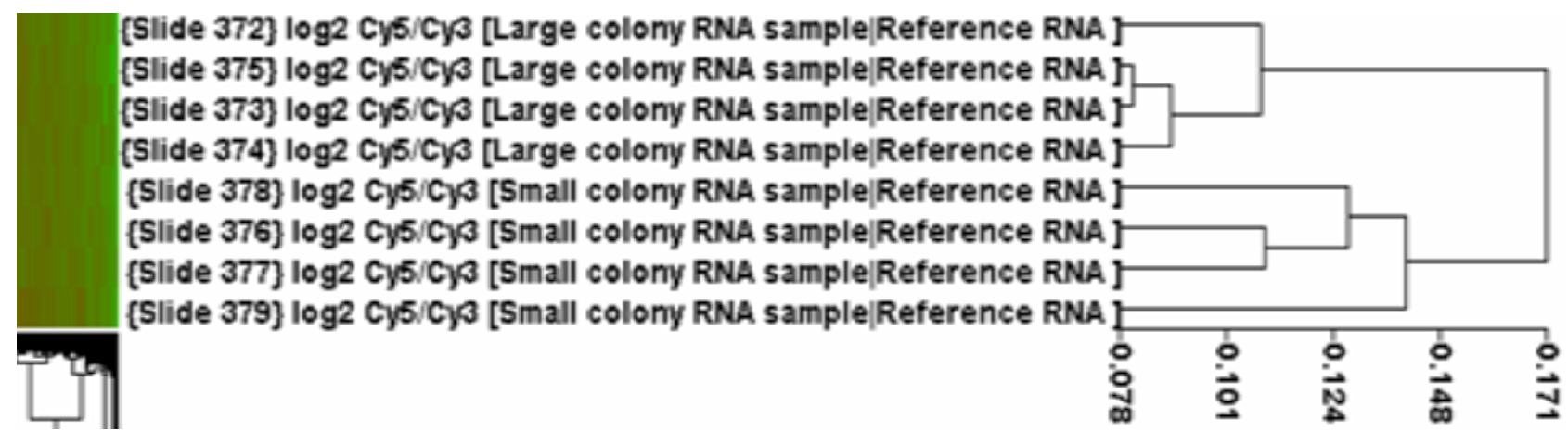

Figure 4

Hierarchical clustering of large and small colony mutant samples. Ward's Minimum Variance method was used. Clustering is based on $\log 2$ ratios and the expression profiles are across all the 20,000 genes in the microarrays.

to cell growth. It is expected that one or more genes located near the Tk gene on chromosome 11 may have differential expression in large and small colony mutants because of an alteration of the DNA in the region around the Tk gene. The Gene Library feature of ArrayTrack was used to identify the significant genes located on chromosome 11. Among 90 significant genes, 10 of them were found to be located on chromosome 11 (about 11\%). Interestingly, all these genes had a higher gene expression in small colony mutants than in large colony mutants (Table 1 and Figure 6). Among the total genes $(20,000)$ in the array, about $5.6 \%$ of them are located on chromosome 11 and no bias for up or down-regulation of genes was found.

\section{Discussion}

The large and small colony $T k$ mutants differ in their growth kinetics. The cells from the small colony mutants grow slowly while the cells from large colony mutants grow at normal rates $[5,9]$. The relative proportion of these two classes of mutants is mutagen dependent and relates to the clastogenic, anuploidogenic and recombinogenic potential of the chemical. Despite extensive molecular genetic and cytogenetic evaluation of a large number of mutants, the fundamental mechanistic difference(s) between the two phenotypes is not known. To explore the biological difference between the two types of Tk mutants, four large colony mutant samples with an average doubling time of $9.6 \pm 0.2$ hours and four small colony mutant samples with an average doubling time of $17.5 \pm$ 0.4 hours were examined by microarray gene expression analysis.

PCA and HCA of the gene expression profiles from these mutant samples showed that the samples were clearly sep- arated into two groups based on their phenotype of colony sizes. Given that both PCA and HCA were conducted using all of the genes on the microarray (20K) without filtering, this finding is very significant, indicating a high quality of the microarray experiment and strong biological relevance. The results can be interpreted as evidence for the biological similarity within each size group and biological differences between the two different size colony mutants. Also the results from PCA (Figure 3) showed that the gene expression patterns in the large colony group of mutants were very homogeneous while the expression patterns from the small colony group of mutants were relatively heterogeneous. These patterns reflect the variability of the colony size in the two groups. Generally, large colony mutants are similar in size to wild-type colonies; the growth rate of these cells is also similar. The growth rate of cells in the small colony mutants is slower and more variable than wild-type cells. The standard deviation of the growth rate of cells from the small colony mutant samples was greater than that for cells from the large colony mutants.

Expression of 90 genes was significantly altered between large and small colony mutants. When comparing the expression of large colony mutants to small colony mutants, 15 genes were up-regulated and 75 genes were down-regulated. This bias might result from the characteristics of these genes. Most of these genes are involved in regulation of growth. Twenty-two of 50 genes mapped into IPA database were involved in the regulation of apoptosis. They are Cdh2, Cdkn2A, Chrm1, Cspg2, Ets1, Fgfr1, Gata6, Grn, Ifi202b, Il17rd, Irf2, Lamb2, Neu3, Nppa, Pdgfra, Ptn, Ptprc, Rag2, Sema3b, Stat1, Tgfbr2, and Tp53inp1. Expression of 18 genes among them was higher in small colony mutants than large colony 
mutants. This pattern of expression suggests that more apoptosis occurred in the small colony mutants, leading to the slow growth of the cells.

Consistent with the growth rate phenotype is the finding that nearly all significant genes that can be found in IPA database were mapped into networks that were related to cell growth (see Table 2).

Genes of particular interest in this group are recombination activating gene 2 (Rag2) and cyclin-dependent kinase inhibitor $2 \mathrm{~A}(\mathrm{Cdkn} 2 \mathrm{a})$. Because a large portion of $T k$ mutants may result from recombinational events, we have proposed that the mouse lymphoma cells have a high recombinase activity. The Rag1 and Rag2 genes are necessary for $\mathrm{V}(\mathrm{D}) \mathrm{J}$ recombination [24,25]. Also, Rag2 is necessary for lymphocyte maturation and growth [26,27]. A 2.21-fold lower activity of Rag2 gene expression in small colony mutant (Table 1) would restrict the cell growth of small colony mutants. Because the large colony cells grow at a similar growth rate as the wild type mouse lymphoma cells, the high expression of Rag2 in large colony cells might suggest that mouse lymphoma cells have an elevated level of the recombinase activity and these cells might be particularly sensitive to recombination and therefore particularly effective in detecting chemicals that induce recombination. Cdkn2a is known to be an important tumor suppressor gene [28] and generates several transcript variants that function as inhibitors of CDK4 kinase $[28,29]$. This protein also sequesters MDM1, a protein involved in the degradation of p53, and thus may serve to stabilize p53 [30]. Therefore, this protein functions in cell cycle control and it is frequently mutated or deleted in a wide variety of tumors [31-35]. A 2.02-fold higher expression activity of this tumor suppressor gene in small colony mutants (Table 1) would favor a slower growth of those cells than the large colony cells.

Of particular interest, the significant genes were disproportionally distributed in the vicinity of the $T k$ gene on chromosome 11 with a higher expression level in small mutant colony mutants than in large colony mutants. Ten of the significant genes were located on chromosome 11. However, if the genes were distributed on the chromosomes proportionally, there would have been about 2 genes with up-regulation of expression in the small colony mutants on chromosome 11 . Moreover, 7 of the 10 genes were located within $20 \mathrm{cM}$ of the Tk gene (Figure 6). This gene distribution pattern may be explained by chromosomal location rather than by gene function, suggesting a regional change in gene expression. Further, this suggests that the type of DNA alteration that inactivates the $T k$ gene in the small colony mutants is responsible for this regional change in gene activity. Although the microsatellite LOH pattern in the D and E bands of chromo- some 11 (Figure 2 and Figure 6) was the same for all the mutants, the gene expression in this region appeared significantly different between the large and small colony mutants.

\section{Conclusion}

The PCA and HCA showed that the gene expression profiles from the mutant samples were clearly separated into two groups based on their colony sizes. This cluster pattern indicates biological similarity within each mutant group and biological difference between the two different colony size mutants. Statistical and functional analysis of the profiles identified a set of genes whose expression was differentially altered between large and small colony mutants. Most of these genes are responsible for regulation of cell growth that would be expected to influence the cell growth rate and the colony sizes. In addition, we found a number of significant genes that were disproportionally concentrated on an area of chromosome 11 where there was loss of heterozygosity. These findings suggest that the $T k$ chromosome mutations in the small $T k$ colony mutants result in alterations in gene expression for genes located near the $T k$ gene. This same altered gene expression does not occur in the large colony mutants. This finding is particularly interesting because the microsatellite LOH analysis indicates no difference between the small and large colony mutants. Our analysis demonstrates that the utility of microarray analysis using ArrayTrack provides a gene level analysis of the two cellular phenotypes. Using this tool, we have identified genes that appear to be related to the colony size phenotype. The analysis of additional mutants would be expected to provide further information and may elucidate the underlying difference between the small and large colony $T k$ mutants.

\section{Authors' contributions}

$\mathrm{TH}$ performed the experiments for generating the original data and was involved in writing the manuscript. JCF and $\mathrm{TH}$ did the original microarray data analysis. JW generated the mutant cells; tested the genotypes of the mutants; isolated the mRNA from the mutants; and was involved in the experimental design. WT, MMM and JCF participated in the overall design of the study, discussion of the data analysis, and assistance with writing the manuscript. TC had the original idea for this study, performed the data analysis, and wrote the manuscript. All authors approved the final manuscript. 


\section{$80(15$ un,75 dewni Fuly Significant}

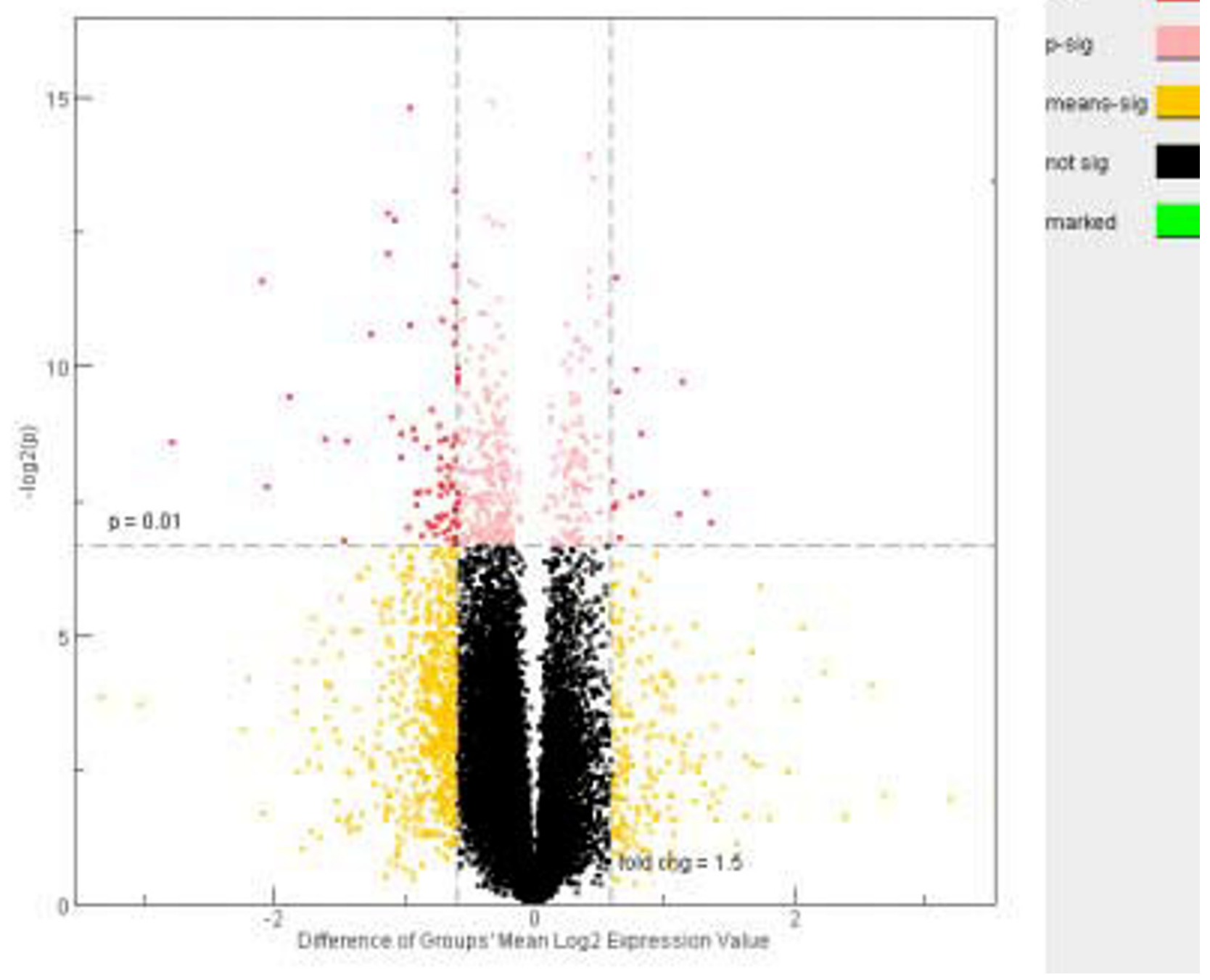

Figure 5

Volcano plot for differentially expressed genes between large and small colony mutants. The plot is based on log 2 ratios and the expression profiles are across all the 20,000 genes in the microarrays. A gene is identified as significantly altered if the $p-$ value is smaller than 0.01 and fold change is greater than I.5. Red dots indicate significant genes; pink dots indicate genes that have $p<0.01$ and fold changes $<1.5$; yellow dots indicate genes that have $p>0.01$ and fold change $>1.5$; and black dots indicate genes that have $p>0.01$ and fold change $<$ I.5. 
Table I: Genes differentially expressed between large and small colony mutants $(p<0.0 \mathrm{I}$; fold change $>I .5)$.

\begin{tabular}{|c|c|c|c|c|}
\hline Locus ID & Gene Name & $P$ Value & Fold Change & Description \\
\hline 109815 & $\mathrm{H} 47$ & 0.0000 & -1.55 & histocompatibility 47 \\
\hline 93707 & Pcdhgc4 & 0.0000 & -1.93 & protocadherin gamma subfamily C, 4 \\
\hline 100121 & 5730495 N IORik & 0.0001 & 11.68 & tudor domain containing 7 \\
\hline 23936 & LynxI & 0.0001 & $-|.5|$ & Ly6/neurotoxin I \\
\hline 74558 & $9130002 C 22$ Rik & 0.0001 & -2.18 & GTPase, very large interferon inducible I \\
\hline 77705 & 9230104L09Rik & 0.0002 & -2.10 & RIKEN cDNA 9230104L09 gene \\
\hline 18028 & $N f i b$ & 0.0002 & -2.19 & nuclear factor I/B \\
\hline$|408|$ & Acsll & 0.0003 & 1.55 & acyl-CoA synthetase long-chain family member I \\
\hline 12669 & Chrml & 0.0003 & -1.53 & cholinergic receptor, muscarinic I, CNS \\
\hline 14824* & Grn & 0.0003 & -4.26 & granulin \\
\hline 60599 & $\operatorname{Trp53inpl}$ & 0.0004 & -1.54 & transformation related protein 53 inducible nuclear protein I \\
\hline $268490 *$ & III0032El6Rik & 0.0006 & -1.53 & RIKEN cDNA 260000 IBI 7 gene \\
\hline 68473 & I I l0003E08Rik & 0.0006 & -1.63 & MOBI, Mps One Binder kinase activator-like IA (yeast) \\
\hline 16391 & $\operatorname{lsg} 3 g$ & 0.0006 & -1.93 & interferon dependent positive acting transcription factor 3 gamma \\
\hline 14182 & Fgfrl & 0.0008 & -1.53 & fibroblast growth factor receptor I \\
\hline 71723 & $\operatorname{Dh} \times 34$ & 0.0010 & 1.73 & DEAH (Asp-Glu-Ala-His) box polypeptide 34 \\
\hline 494468 & MGC38735 & 0.0010 & $-1.5 \mid$ & hypothetical protein \\
\hline $20742 *$ & Spnb2 & 0.0011 & -1.50 & spectrin beta 2 \\
\hline 19374 & Rag2 & 0.0012 & 2.21 & recombination activating gene 2 \\
\hline $18103 *$ & Nme2 & 0.0012 & -1.50 & expressed in non-metastatic cells 2 , protein \\
\hline 66359 & 2310005 N03Rik & 0.0014 & 1.56 & RIKEN cDNA 23I0005N03 gene \\
\hline 194367 & & 0.0015 & -3.69 & Not found \\
\hline 72700 & 2810040004 Rik & 0.0017 & -1.73 & Zinc fingerprotein 618 \\
\hline 231293 & Cl30090K23Rik & 0.0019 & -2.14 & RIKEN cDNA CI30090K23 gene \\
\hline 27660 & I 700088E04Rik & 0.0021 & -1.66 & RIKEN cDNA I700088E04 gene \\
\hline 55932 & Gbp3 & 0.0022 & -1.91 & guanylate nucleotide binding protein 4 \\
\hline 19245 & Ptp $4 a 3$ & 0.0024 & 1.77 & protein tyrosine phosphatase $4 \mathrm{a} 3$ \\
\hline 17722 & Nd6 & 0.0024 & -1.53 & NADH dehydrogenase subunit 6 \\
\hline 12578 & Cdkn2a & 0.0024 & -2.02 & cyclin-dependent kinase inhibitor $2 \mathrm{~A}$ \\
\hline 20846 & Statl & 0.0026 & -1.52 & signal transducer and activator of transcription I \\
\hline 77015 & 2700082015 Rik & 0.0026 & $-1.6 \mid$ & metallophosphoesterase domain containing 2 \\
\hline 50877 & Neu3 & 0.0026 & -1.65 & neuraminidase 3 \\
\hline 67998* & I3000I0M03Rik & 0.0026 & -1.88 & RIKEN cDNA I3000I0M03 gene \\
\hline $17 \mid 463$ & III 7rd & 0.0026 & -2.72 & interleukin 17 receptor D \\
\hline 20363 & Seppl & 0.0026 & -3.05 & selenoprotein $\mathrm{P}$, plasma, I \\
\hline 12833 & Colbal & 0.0026 & -6.94 & procollagen, type VI, alpha I \\
\hline 13612 & Edil3 & 0.0028 & -1.54 & EGF-like repeats and discoidin I-like domains 3 \\
\hline 77773 & A330I03N2 I Rik & 0.0028 & -1.77 & RIKEN cDNA A330I03N2I gene \\
\hline 228543 & Arhv & 0.0032 & -2.04 & ras homolog gene family, member $V$ \\
\hline 230899 & Nppa & 0.0033 & -1.52 & natriuretic peptide precursor type $A$ \\
\hline 3337208 & Cytb & 0.0033 & -1.65 & cytochrome b \\
\hline 12558 & Cdh2 & 0.0037 & -1.57 & cadherin 2 \\
\hline $192231 *$ & Clpl & 0.0037 & -1.67 & hexamethylene bis-acetamide inducible I \\
\hline 93875 & Pcdhb4 & 0.0041 & -1.58 & protocadherin beta 4 \\
\hline 72080 & 20103 I 7E24Rik & 0.0044 & 1.51 & RIKEN cDNA 20103I7E24 gene \\
\hline 27360 & Add3 & 0.0045 & -1.57 & adducin 3 (gamma) \\
\hline |443| & Gamt & 0.0046 & -1.65 & guanidinoacetate methyltransferase \\
\hline$|384|$ & Epha7 & 0.0047 & -1.55 & Eph receptor A7 \\
\hline 21356 & $T a p b p$ & 0.0047 & -1.63 & TAP binding protein \\
\hline 26388 & Ifi202b & 0.0047 & -4.15 & interferon activated gene $202 \mathrm{~B}$ \\
\hline 77974 & Rdh 12 & 0.0050 & -1.60 & retinol dehydrogenase 12 \\
\hline 11542 & Adora3 & 0.0050 & -1.76 & adenosine $\mathrm{A} 3$ receptor \\
\hline 16909 & Lmo2 & 0.0050 & -1.84 & LIM domain only 2 \\
\hline 16779 & Lamb2 & 0.0051 & 2.50 & laminin, beta 2 \\
\hline 19264 & Ptprc & 0.0051 & 1.78 & protein tyrosine phosphatase, receptor type, $C$ \\
\hline 57754 & 150000 IHI 2 Rik & 0.0051 & -1.50 & RIKEN cDNA I $50000 \mathrm{IHI} 2$ gene \\
\hline 225849 & $\operatorname{Ppp} 2 r 5 b$ & 0.0051 & -1.88 & protein phosphatase 2 , regulatory subunit $B(B 56)$, beta isoform \\
\hline 15950 & Ifi203 & 0.0052 & -1.65 & interferon activated gene 203 \\
\hline 258568 & MOR202-20 & 0.0053 & 1.68 & olfactory receptor 1457 \\
\hline
\end{tabular}


Table I: Genes differentially expressed between large and small colony mutants $(p<0.0 \mathrm{I}$; fold change $>$ I.5). (Continued)

\begin{tabular}{|c|c|c|c|c|}
\hline $2387 \mid$ & EtsI & 0.0058 & 1.54 & E26 avian leukemia oncogene $1,5^{\prime}$ domain \\
\hline 21813 & Tgfbr2 & 0.0058 & -1.50 & transforming growth factor, beta receptor II \\
\hline 65116 & Prrg2 & 0.0060 & -1.52 & proline-rich Gla (G-carboxyglutamic acid) polypeptide 2 \\
\hline 192231 & Clpl & 0.0060 & -1.88 & hexamethylene bis-acetamide inducible I \\
\hline $2064 \mid$ & SnrpdI & 0.0062 & 1.54 & small nuclear ribonucleoprotein DI \\
\hline $252868 *$ & Oppol & 0.0062 & -1.52 & outer dense fiber of sperm tails 4 \\
\hline 380832 & Tcrg-C & 0.0066 & 2.17 & T-cell receptor gamma, constant region \\
\hline $24086^{*}$ & Tlk2 & 0.0067 & -1.61 & tousled-like kinase 2 (Arabidopsis) \\
\hline 67775 & $5830458 K / 6 R i k$ & 0.0068 & -1.64 & RIKEN cDNA 5830458K 16 gene \\
\hline 15042 & $\mathrm{H} 2-\mathrm{T} 24$ & 0.0069 & -1.68 & histocompatibility $2, T$ region locus 24 \\
\hline 24066 & Spry4 & 0.0071 & -1.51 & sprouty homolog 4 (Drosophila) \\
\hline 15425 & Hoxc6 & 0.0071 & -1.65 & homeo box $\mathrm{C} 6$ \\
\hline | 4934 & Gypa & 0.0074 & 2.57 & glycophorin A \\
\hline 230587 & Gli6 & 0.0074 & -1.55 & GLIS family zinc finger I \\
\hline 19242 & Ptn & 0.0074 & -1.77 & pleiotrophin \\
\hline 211770 & A5300900I5Rik & 0.0077 & -1.51 & tribbles homolog I (Drosophila) \\
\hline 20128 & Trim30 & 0.0077 & -1.70 & tripartite motif protein 30 \\
\hline 22441 & $X I r$ & 0.0079 & -1.73 & X-linked lymphocyte-regulated complex \\
\hline 66205 & II I 0055 L24Rik & 0.0079 & -1.96 & CD302 antigen \\
\hline $70110 *$ & $2010008 K / 6 R i k$ & 0.0081 & -1.58 & interferon-induced protein 35 \\
\hline 214855 & D430024K22Rik & 0.0084 & -1.62 & AT rich interactive domain $5 \mathrm{~A}$ (Mrfl like) \\
\hline 13003 & Cspg2 & 0.0086 & -1.70 & chondroitin sulfate proteoglycan 2 \\
\hline 70355* & Gprc5c & 0.0087 & -1.82 & G protein-coupled receptor, family $C$, group 5 , member $C$ \\
\hline 67974 & 5730405109Rik & 0.0089 & 1.58 & RIKEN cDNA 5730405109 gene \\
\hline 20347 & Sema3b & 0.0091 & -1.53 & sema domain, immunoglobulin domain (lg), short basic domain, secreted, (semaphorin) 3B \\
\hline 16364 & Irf4 & 0.0092 & -1.60 & interferon regulatory factor 4 \\
\hline 18595 & Pdgfra & 0.0095 & -2.77 & platelet derived growth factor receptor, alpha polypeptide \\
\hline 14465 & Gata6 & 0.0097 & -1.53 & GATA binding protein 6 \\
\hline
\end{tabular}

Note: Three unknown genes are not included. ${ }^{*}$ indicates the gene is located on chromosome II.

Table 2: List of Ingenuity networks generated by mapping the focus genes that were differentially expressed between large and small colony mutants.

\begin{tabular}{|c|c|c|c|c|}
\hline Network & Genes* & Score $\#$ & Focus Genes & Top Functions \\
\hline I & $\begin{array}{l}\text { Add3, Adora3, Agt, Asflb, Cdknlb, Cdkn2a, Ckslb, } \\
\text { Col6a I, Col6a2, Cspg2, Ctcf, Cypl I Ib2, Egfr, Eps8, Erbb2, } \\
\text { Fbn I, Fgfrl, Gbp4, Gpcl, Hmga2, III Ird, Irf4, Mell I, } \\
\text { Nfatc2, Nfib, Nppa, Npr3, P4ha2, Ptrf, Rag2, Tgfbr2, } \\
\text { Tlk2, Topl, Tp53inpI, Wap }\end{array}$ & 25 & 15 & $\begin{array}{l}\text { Cellular Growth and Proliferation, Cancer, Cell } \\
\text { Death }\end{array}$ \\
\hline 2 & $\begin{array}{l}\text { Acsl I, Angptl, Btgl, Btg2, Ccntl, Ccnt2, Cdk9, Cebpa, } \\
\text { Chrm I, Dgkz, Efnal, ElfI, Epha7, Fbl, Grn, His I, Ifi203, } \\
\text { Lamb2, MapkI, MmpI7, Myc, Nme2, Oas I, Ptprc, Ptx3, } \\
\text { RasgrpI, Rn7sk, RockI, Slpi, Spry4, SytlI, Tapbp, Tdrd7, } \\
\text { Tnf, Trib I }\end{array}$ & 21 & 13 & $\begin{array}{l}\text { Gene Expression, Cellular Development, Cell- } \\
\text { To-Cell Signaling and Interaction }\end{array}$ \\
\hline 3 & $\begin{array}{l}\text { AloxI5, Btgl, Cdkn la, Cks Ib, Col6a I, Col6a2, Col6a3, } \\
\text { Ctcf, Ebi3, FgII3, Gata6, Gvin I, Ifi35, Ifi202b, Ifna, Ifne I, } \\
\text { Ifng, III5, III 2rb I, III If, II27ra, Isgf3g, Mylk, Nd6, Ndufs4, } \\
\text { Pdgf, Pdgfra, SI00a I I, Sema3b, Sepp I, Stat I, Stat4, } \\
\text { Tgfb I, Trim30, Znf467 }\end{array}$ & 19 & 12 & $\begin{array}{l}\text { Cancer, Cell Death, Cellular Growth and } \\
\text { Proliferation }\end{array}$ \\
\hline 4 & $\begin{array}{l}\text { Casp3, Cckbr, CdId, Cdh2, Ctcf, Ctnna2, Ctnnbl, Ctnnd2, } \\
\text { Cyp24a I, Edil3, Ets I, Gypa, II2, Invs, Lmo2, Mdm4, } \\
\text { Mgat5, Neu3, Nf2, Pag, Pitx2, Ppp2ca, Ppp2cb, Ppp2r2c, } \\
\text { Ppp2r5b, Ptn, Ptp4a3, Ptprc, Scn5a, Slc4a I, SnrpdI, } \\
\text { Sptbn I, Tbxas I, Tp53, Tubal }\end{array}$ & 19 & 12 & $\begin{array}{l}\text { Cellular Development, Hematological System } \\
\text { Development and Function, Immune and } \\
\text { Lymphatic System Development and Function }\end{array}$ \\
\hline
\end{tabular}

Note: * Bold genes are those mapped by the significant genes. ${ }^{\#}$ A score of 3 or greater was considered significant $(p<0.00 \mathrm{I})$ 


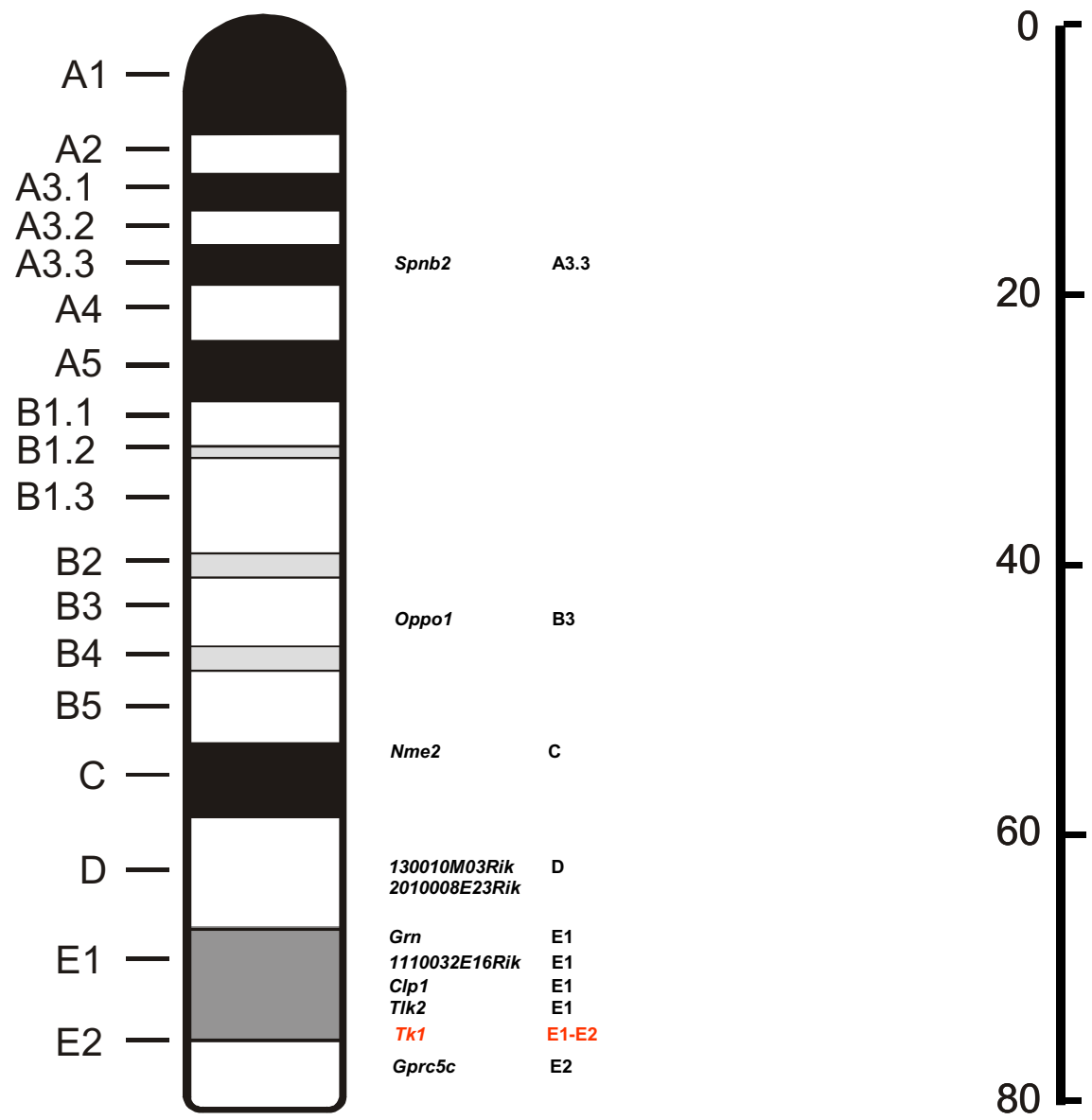

Figure 6

Map for chromosome II genes whose expression was significantly altered. The position of $T k I$ gene in red is also shown for comparison. The right ruler indicates distance in $\mathrm{CM}$ (centimorgan) from top of the chromosome.

Table 3: Location and function of the significant genes located on chromosome II.

\begin{tabular}{lll}
\hline \multicolumn{1}{c}{ Gene Name } & Location & \\
\hline III0032EI6Rik & EI & Hypothetical protein LOC268490 with unknown function \\
13000I0M03Rik & D & Hypothetical protein LOC67998 with unknown function \\
$2010008 K$ I6Rik & D & Interferon-induced protein with unknown function \\
ClpI & EI & Cleavage and polyadenylation factor CF I component involved in pre-mRNA 3'-end processing \\
Gprc5c & E2 & G protein-coupled receptor, family C, group 5, member C with unknown function \\
Grn & EI & Granulin that acts as inhibitors, stimulators, or have dual actions on cell growth. \\
Nme2 & C & Expressed in non-metastatic cells 2, protein involves in cell proliferation. \\
Oppol & B3 & Outer dense fiber of sperm tails 4 with unknown function. \\
Spnb2 & A3.3 & Spectrin involving disruption, proliferation of cells. \\
Tlk2 & EI & Tousled-like kinase 2 that function as regulation of chromatin assembly or disassembly; protein amino acid \\
& & phosphorylation; response to DNA damage stimulus; cell cycle; intracellular signaling cascade; chromatin modification
\end{tabular}




\section{Acknowledgements}

The authors thank Mr. William S. Branham for fabricating the high-quality microarrays used in this study. The views presented in this article do not necessarily reflect those of the Food and Drug Administration.

\section{References}

I. Dearfield KL, Auletta AE, Cimino MC, Moore MM: Considerations in the U.S. Environmental Protection Agency's testing approach for mutagenicity. Mutat Res 1991, 258:259-283.

2. Department of Health and Human Services: Genotoxicity: A Standard Battery for Genotoxicity Testing of Pharmaceuticals. International Conference on Harmonization of Technical Requirements for Registration of Pharmaceuticals for Human Use. Food and Drug Administration, Rockville, MD; 1997.

3. Muller L, Kikuchi Y, Probst G, Schechtman L, Shimada H, Sofuni T, Tweats D: ICH-harmonised guidances on genotoxicity testing of pharmaceuticals: evolution, reasoning and impact. Mutat Res 1999, 436(3): 195-225.

4. Chen T, Moore MM: Screening for chemical mutagens using the mouse lymphoma assay. In Optimization in Drug Discovery: Invitro Methods Edited by: Yan Z, Caldwell GW. Totowa, New Jersey: Humana Press; 2004:337-352.

5. Moore MM, Clive D, Howard BE, Batson AG, Turner NT: In situ analysis of trifluorothymidine-resistant (TFTr) mutants of L5I78Y/TK+/- mouse lymphoma cells. Mutat Res 1985, I 5 I(I): I47-I59.

6. Moore MM, Brock KH, Doerr CL, DeMarini DM: Mutagenesis of L5I78Y/TK(+/-)-3.7.2C mouse lymphoma cells by the clastogen ellipticine. Environ Mutagen 1987, 9(2): I6I-I70.

7. Chen T, Harrington-Brock K, Moore MM: Mutant frequency and mutational spectra in the Tk and Hprt genes of $\mathbf{N}$-ethyl-Nnitrosourea-treated mouse lymphoma cellsdagger. Environ Mol Mutagen 2002, 39(4):296-305.

8. Chen T, Harrington-Brock K, Moore MM: Mutant frequencies and loss of heterozygosity induced by $\mathbf{N}$-ethyl- $\mathbf{N}$-nitrosourea in the thymidine kinase gene of L5 I 78Y/TK(+/-)-3.7.2C mouse lymphoma cells. Mutagenesis 2002, I7(2): I05-109.

9. Moore MM, Clive D, Hozier JC, Howard BE, Batson AG, Turner NT Sawyer J: Analysis of trifluorothymidine-resistant (TFTr) mutants of L5 I 78Y/TK+/- mouse lymphoma cells. Mutat Res 1985, I 5 I(I): 161-174.

10. Hozier J, Sawyer J, Clive D, Moore MM: Chromosome I I aberrations in small colony L5 I78Y TK-/- mutants early in their clonal history. Mutat Res 1985, I 47(5):237-242.

II. Applegate ML, Moore MM, Broder CB, Burrell A, Juhn G, Kasweck $\mathrm{KL}$, Lin PF, Wadhams A, Hozier JC: Molecular dissection of mutations at the heterozygous thymidine kinase locus in mouse lymphoma cells. Proc Natl Acad Sci USA 1990, 87( I):5I-55.

12. Moore MM, Doerr CL: Comparison of chromosome aberration frequency and small-colony TK-deficient mutant frequency in L5 I 78Y/TK(+/-)-3.7.2C mouse lymphoma cells. Mutagenesis |990, 5(6):609-614.

13. Hozier J, Sawyer J, Moore M, Howard B, Clive D: Cytogenetic analysis of the L5I78Y/TK $K^{+/-}$leads to $T K^{-1-}$ mouse lymphoma mutagenesis assay system. Mutat Res I98I, 84(I): |69-I8I.

14. Liechty MC, Scalzi JM, Sims KR, Crosby H Jr, Spencer DL, Davis LM, Caspary WJ, Hozier JC: Analysis of large and small colony L5 I 78 Y tk-l- mouse lymphoma mutants by loss of heterozygosity (LOH) and by whole chromosome I I painting: detection of recombination. Mutagenesis 1998, I3(5):46 I-474

15. Honma M, Momose M, Sakamoto H, Sofuni T, Hayashi M: Spindle poisons induce allelic loss in mouse lymphoma cells through mitotic non-disjunction. Mutat Res 2001, 493(I-2): I0I-I |4.

16. Weinert TA, Hartwell LH: The RAD9 gene controls the cell cycle response to DNA damage in Saccharomyces cerevisiae. Science 1988, 24 I (4863):3 I7-322.

17. Lock RB, Ross WE: Inhibition of p34cdc2 kinase activity by etoposide or irradiation as a mechanism of $\mathbf{G 2}$ arrest in Chinese hamster ovary cells. Cancer Res 1990, 50( I 2):376I-3766.

18. Kowara R, Karaczyn A, Cheng RY, Salnikow K, Kasprzak KS: Microarray analysis of altered gene expression in murine fibroblasts transformed by nickel(II) to nickel(II)-resistant malignant phenotype. Toxicol Appl Pharmacol 2005, 205(I): I-I0.

19. Nishizuka S, Winokur ST, Simon M, Martin J, Tsujimoto H, Stanbridge EJ: Oligonucleotide microarray expression analysis of genes whose expression is correlated with tumorigenic and nontumorigenic phenotype of HeLa $\times$ human fibroblast hybrid cells. Cancer Lett 200I, I 65(2):201-209.

20. Ciro M, Bracken AP, Helin K: Profiling cancer. Curr Opin Cell Bio 2003, I 5(2):213-220.

21. Hanash S: Integrated global profiling of cancer. Nat Rev Cancer 2004, 4(8):638-644.

22. Tong $W$, Harris S, Cao X, Fang H, Shi L, Sun H, Fuscoe J, Harris A, Hong $\mathrm{H}$, Xie $\mathrm{Q}$, et al.: Development of public toxicogenomics software for microarray data management and analysis. Mutat Res 2004, 549(I-224I-253 [http://www.fda.gov/nctr/science/ centers/toxicoinformatics/ArrayTrack/].

23. Wang J, Chen L, Chen T, Moore MM: Molecular analysis of spontaneous and 3'-azido-3'-deoxythymidine - induced L5 I78y $\mathbf{T k}^{-/-}$mouse lymphoma cell mutants. The Toxicologist 2005, 84(SI):454.

24. Knecht $H$, Brousset $P$, Bachmann E, Pallesen G, Odermatt BF: Expression of human recombination activating genes (RAG. I and RAG-2) in lymphoma. Leuk Lymphoma I994, I 5(56):399-403

25. Oettinger MA, Schatz DG, Gorka C, Baltimore D: RAG-I and RAG-2, adjacent genes that synergistically activate V(D)J recombination. Science $1990,248(4962)$ : I5I7-| 523.

26. Ohmori $\mathrm{H}$, Hikida $\mathrm{M}$ : Expression and function of recombination activating genes in mature B cells. Crit Rev Immunol 1998 , I 8(3):22|-235.

27. Swat W, Shinkai Y, Cheng HL, Davidson L, Alt FW: Activated Ras signals differentiation and expansion of CD4+8+ thymocytes. Proc Natl Acad Sci USA 1996, 93( I 0):4683-4687.

28. Herzog CR, You M: Sequence variation and chromosomal mapping of the murine Cdkn2a tumor suppressor gene. Mamm Genome 1997, 8(I):65-66.

29. Biden K, Young J, Buttenshaw R, Searle J, Cooksley G, Xu DB, Leggett $B$ : Frequency of mutation and deletion of the tumor suppressor gene CDKN2A (MTSI/p I6) in hepatocellular carcinoma from an Australian population. Hepatology 1997, 25(3):593-597.

30. Stott FJ, Bates S, James MC, McConnell BB, Starborg M, Brookes S, Palmero I, Ryan K, Hara E, Vousden $\mathrm{KH}$, et al.: The alternative product from the human CDKN2A locus, p I 4(ARF), participates in a regulatory feedback loop with p53 and MDM2. Embo I I998, I7( I7):500I-50I4.

31. Bortolotto S, Chiado-Piat L, Cavalla P, Bosone I, Chio A, Mauro A Schiffer D: CDKN2A/p I 6 inactivation in the prognosis of oligodendrogliomas. Int J Cancer 2000, 88(4):554-557.

32. Bortolotto S, Chiado-Piat L, Cavalla P, Bosone I, Mauro A, Schiffer D: CDKN2A/p 16 in ependymomas. J Neurooncol 200I, 54(I):9- I3.

33. Hashemi J, Platz A, Ueno T, Stierner U, Ringborg U, Hansson J: CDKN2A germ-line mutations in individuals with multiple cutaneous melanomas. Cancer Res 2000, 60(24):6864-6867.

34. Schlegel J, Piontek G, Kersting M, Schuermann M, Kappler R, Scherthan $\mathrm{H}$, Weghorst $\mathrm{C}$, Buzard G, Mennel H: The p I 6/Cdkn2a/Ink4a gene is frequently deleted in nitrosourea-induced rat glial tumors. Pathobiology 1999, 67(4):202-206.

35. Suzuki H, Zhou X, Yin J, Lei J, Jiang HY, Suzuki Y, Chan T, Hannon GJ, Mergner WJ, Abraham JM, et al:: Intragenic mutations of CDKN2B and CDKN2A in primary human esophageal cancers. Hum Mol Genet 1995, 4(1 0): 1883-1887.

Publish with BioMed Central and every scientist can read your work free of charge

"BioMed Central will be the most significant development for disseminating the results of biomedical research in our lifetime. "

Sir Paul Nurse, Cancer Research UK

Your research papers will be:

- available free of charge to the entire biomedical community

- peer reviewed and published immediately upon acceptance

- cited in PubMed and archived on PubMed Central

- yours - you keep the copyright
BioMedcentral 